\title{
Are attitudes towards mental health help-seeking associated with service use? Results from the European Study of Epidemiology of Mental Disorders
}

\author{
M. ten Have $\cdot$ R. de Graaf $\cdot$ J. Ormel $\cdot$ G. Vilagut $~$ \\ V. Kovess · J. Alonso - the ESEMeD/MHEDEA 2000 Investigators
}

Received: 28 October 2008/Accepted: 26 March 2009/Published online: 18 April 2009

(C) The Author(s) 2009. This article is published with open access at Springerlink.com

\begin{abstract}
Objective To investigate the prevailing attitudes towards mental health help-seeking in Europe, their correlates, and whether these attitudes are associated with actual service use for mental health problems.

Method Data were derived from the European Study of Epidemiology of Mental Disorders, a survey representative of the adult population of six countries: Belgium, France, Germany, Italy, the Netherlands and Spain $(n=8,796)$. The World Mental Health Composite International
\end{abstract}

The ESEMeD/MHEDEA 2000 Investigators are: Jordi Alonso, Matthias Angermeyer, Herbert Matschinger, Sebastian Bernert, Ronny Bruffaerts, Traolach S. Brugha, Giovanni de Girolamo, Ron de Graaf, Koen Demyttenaere, Isabelle Gasquet, Josep Maria Haro, Steven J. Katz, Ronald C. Kessler, Viviane Kovess, Jean Pierre Lépine, Johan Ormel, and Gemma Vilagut.

M. ten Have $(\bowtie) \cdot$ R. de Graaf

Netherlands Institute of Mental Health and Addiction,

P.O. Box 725, 3500 AS Utrecht, The Netherlands

e-mail: mhave@trimbos.nl

J. Ormel

Interdisciplinary Center for Psychiatric Epidemiology,

Department of Psychiatry, University Medical Center

Groningen, University of Groningen, Groningen,

The Netherlands

G. Vilagut · J. Alonso

Health Services Research Unit, Institut Municipal d'Investigació

Mèdica (IMIM-Hospital del Mar), Barcelona, Spain

G. Vilagut $\cdot$ J. Alonso

CIBER and Espidemiología y Salud Pública (CIBERESP),

Barcelona, Spain

V. Kovess

MGEN Public Health Foundation, Paris 5 University,

Paris, France
Diagnostic Interview was used to assess attitudes and DSM-IV diagnoses. The attitudes referred to beliefs that the respondents would seek professional help when faced with a serious emotional problem, would feel comfortable talking about personal problems with a professional, would not be embarrassed if friends knew about the professional help, and respondents' perceived effectiveness of mental health care.

Results Almost a third of the respondents held the view that professional care was worse than or equal to no help when faced with serious emotional problems. Female gender, being younger than 65 years of age, high income, living in Spain or Italy, presence of mood disorder and previous service use were associated with at least two of the four assessed attitudes towards mental health help-seeking. All four attitudes were significantly associated with mental health care use, also after adjustment for previous service use.

Conclusion The low perceived effectiveness of professional care calls for serious action aiming to improve the visibility and credibility of the mental health care sector.

Keywords Public opinion - Mental health services . Epidemiology · Cultural differences · Population study

\section{Introduction}

Since 1990 several population studies, mostly performed in Germany and the United Kingdom, have investigated beliefs about mental disorders and psychiatric patients; see for a review: [1]. These studies focussed on to what extent mental disorders are recognised as such and examined the prevailing beliefs about the causes and treatment of these illnesses among the public. The majority of these studies 
used case vignettes describing a person with either depression or schizophrenia. Five major findings can be concluded from these population studies. First, many members of the general public could not correctly recognise mental disorders [2-4]. Second, public beliefs about the causes of mental disorders and the effectiveness of various treatments differed greatly from those of mental health professionals [5-7]. Third, a widespread stigma was found towards those who suffer from a mental disorder, especially people with schizophrenia [8-11]. Four, in the majority of studies where the influence of socio-demographic characteristics on beliefs about psychiatric patients was examined, older age, lower education and less familiarity with mental illness were associated with lower tolerance $[12,13]$. The studies did not focus on correlates of a positive attitude towards various treatment options. Five, the few which examined comparisons within and between countries revealed cultural differences in beliefs about mental disorders and psychiatric patients [13-15]. However, the comparisons made focussed on different cultures, resulting in a fragmented and incomplete picture of these differences.

The public's beliefs about the helpfulness of interventions for mental disorders and about psychiatric patients, such as perceiving the mentally ill as dangerous, untrustworthy or having poor social skills, may affect people's perception of mental health services and the sorts of help they would seek in case of mental health problems [16-18]. It is definitely not enough to have evidence-based treatments available if the public does not perceive mental health care as an effective means in dealing with emotional problems or alcohol or drugs problems. However, the prevailing attitudes towards seeking professional help for such problems and to what extent these beliefs actually influence service use for mental health problems are, to our knowledge, not yet investigated on a large scale in Europe.

The studies that focussed on correlates of a positive attitude towards seeking professional help for mental health problems are limited, and were mostly performed in the USA and Canada. They found that prior experience with the mental health care system was associated with a more positive attitude towards help-seeking [19-21]. More favourable attitudes were also found among women [22, $23]$ and younger people [23, 24]. The studies that investigated to what extent attitudes play a role in the use of services for mental health problems in the general population are also limited, and were mostly performed in Australia. One study found that belief in professional help was a significant predictor of actually seeking help for mental health problems [25, 26]. Another study reported that beliefs about the helpfulness of an intervention did not always predict actual use of that intervention. It depended upon the particular intervention. Beliefs did predict use of antidepressants, but not counselling by a general practitioner or mental health professional in case of a mental health problem, even after adjustment for socio-demographic characteristics, previous depression and number of anxiety and depression symptoms [27]. In contrast, a third study among young adults found that beliefs about the effectiveness of mental health treatment were associated with use of mental health services, after controlling for socio-demographic characteristics, mental health symptoms and subjective need [28].

The few studies which have examined correlates of a positive attitude towards seeking professional help for mental health problems and to what extent such attitude actually influences mental health care use have two major limitations. They were not based on a large representative sample of the general population, and the findings were not controlled for the presence of a mental disorder. It is conceivable, however, that persons with a mental disorder differ in their opinion towards mental health care based on their experience or mental state. To effectively organise health education campaigns, more information is needed about how the general public and certain patient groups differ in their perception of the mental health care sector as an effective means in dealing with emotional problems, and subsequently to what extent attitude towards mental health care is a significant predictor of service use.

This paper attempts to fill this lack of knowledge by addressing three questions in a general population study performed in six European countries, using the Composite International Diagnostic Interview to determine attitudes towards health care and psychiatric diagnoses:

1) What are the prevailing attitudes towards mental health help-seeking in Europe?

2) What are correlates of these attitudes?

3) To what extent are these attitudes associated with actual service use for mental health problems?

\section{Methods}

Sample

Data were derived from the European Study of Epidemiology of Mental Disorders (ESEMeD). Methods have been reported elsewhere [29]. Briefly, ESEMeD is a crosssectional survey representative of the adult population of six European countries: Belgium, France, Germany, Italy, the Netherlands and Spain $(N=21,425)$. It is based on a multistage, stratified, random sampling procedure of households. Respondents were contacted and one respondent was randomly chosen in each household on the condition that she/he was 18 years of age or older, and 
sufficiently fluent in the language of assessment, to be interviewed. Face-to-face interviews took place between January 2001 and July 2003 and the overall response rate of the study was $61.2 \%$. Men and the youngest age groups (18-34 years of age) were somewhat under-represented.

The ethics committees in each participating country approved the survey procedures. An informed consent was obtained from all respondents after having been informed about the aims of the study.

\section{Diagnostic interview}

The World Mental Health Composite International Diagnostic Interview (CIDI version 3.0) [30], computerised version was used to determine DSM-IV diagnoses. The CIDI 3.0 is a fully structured interview developed and adapted by the Coordinating Committee of the World Health Organization World Mental Health 2000 Initiative. The CIDI 3.0 is designed for use by trained non-clinicians. Research has demonstrated acceptable reliability and validity [31] for virtually all CIDI diagnoses.

The CIDI 3.0 was first produced in English and underwent a rigorous process of adaptation in order to obtain conceptually and cross-culturally comparable versions in each of the target countries and languages. This process included forward and backward translations, a review by a panel of experts, pretesting using cognitive interview and debriefing techniques and the intervention of focus groups.

The interview schedule consists of two parts. All respondents completed Part I, which contained core diagnostic assessments, service use, and socio-demographics. All Part I respondents who met criteria for any of these core disorders plus a $25 \%$ probability sub-sample of other Part I respondents were administered Part II, which assessed disorders of secondary interest (the less prevalent disorders such as post-traumatic stress disorder and obsessive-compulsive disorder) and a wide range of correlates. Attitudes towards mental health help-seeking were assessed in Part II. For this reason, the data presented here are from the subsample of respondents who completed Part II $(n=8,796)$.

\section{Mental disorders}

In this paper the following 12-months DSM-IV diagnoses of Part I were included: mood disorders (depression, dysthymia), anxiety disorders (panic disorder, agoraphobia, social phobia, simple phobia, generalised anxiety disorder), and alcohol disorders (abuse, dependence). Any previous mental disorder, based on the above-mentioned disorders, was assessed in the period before the past 12 months. The hierarchical rules as prescribed by DSM-IV were applied in the analyses reported here.
Attitudes towards mental health help-seeking

In the WMH-CIDI Part II five questions concerning the respondent's attitudes towards mental health help-seeking were asked, based on previous population studies explaining variations in service use [32-35] such as the National Comorbidity Survey [36].

1) If you had a serious emotional problem, would you go for professional help? Answer categories were: definitively not go, probably not go, probably go and definitively go.

2) How comfortable would you feel talking about personal problems with a professional? Answer categories were: not at all, not very, somewhat and very comfortable.

3) How embarrassed would you be if your friends knew you were getting professional help for an emotional problem? Answer categories were: very, somewhat, not very and not at all embarrassed.

4) Of the people who see a professional for serious emotional problems, what percent do you think are helped? Answers could vary between 0 and $100 \%$.

5) Of those with serious emotional problems who do not get professional help, what percent do you think get better even without it? Answers could vary between 0 and $100 \%$.

To get a constructed variable with the meaning 'perceived effectiveness of professional help', the percentages on the last two questions were subtracted (question 4 minus question 5) and then these answers were divided into four categories: (1) worse than or equal to no help, (2) somewhat, the first $33 \%$ that indicated that professional help was, better than no help, (3) considerable, the second $33 \%$ that indicated that professional help was, better than no help and (4) much, the third 33\% that indicated that professional help was, better than no help.

\section{Service use}

Service use refers to at least one contact made in the general health care sector or the mental health care sector for problems with one's emotions or mental health in the past 12 months. General health care includes general practitioners, medical specialists and other health care professionals working in this sector, such as nurses and nutritionists. Mental health care includes psychiatrists, and other mental health care professionals working in this sector, such as psychologists, psychotherapists and social workers. Because correlates of service use vary according to the sector in which help is sought [37], we defined two types of service users: those using general health care only, and those using mental health care with or without general health care. 
Correlates of attitudes towards mental health helpseeking and service use.

The following correlates of attitudes and service use were recorded:

- Socio-demographic characteristics: gender, age (in six categories), education (in two categories), living with partner, paid employment, income (in four categories), urbanicity of place of residence (three categories: low $=$ less than 10,000 inhabitants; middle = between 10,000 and 100,000 inhabitants; high $=$ more than 100,000 inhabitants), and country (6).

- Mental disorders: any mood disorder, any anxiety disorder and any alcohol disorder (all assessed in the past 12 months), and any previous mental disorder.

- Emotional role impairments were assessed in the past 4 weeks with the mental component summary (MCS) scale of the Short-Form 12 (SF-12) [38]. This scale was dichotomised using the cut-off point, which is available for the MCS of the Short-Form 36 (SF-36) (lowest through $42=1 ; 43$ through highest $=0$ ) [see 39]. Given the fact that the SF-12 is the short version of the SF-36 and that the MCS of the SF-12 reproduces more than $90 \%$ of the MCS's variance based on the SF-36 [40], the same cut-off point was used.

- Parental psychiatric history was assessed by asking respondents whether one or both parents had ever exhibited major depression, generalised anxiety disorder, panic disorder or alcohol disorder.

- Service use: see above (this variable was included as a correlate of attitudes).

\section{Statistical analyses}

All analyses were weighted to account for the different probabilities of selection within households and for the selection of individuals in the Part II sample, as well as to restore the age and gender distribution of the population within each country and the relative dimension of the population across countries. All parameters were estimated using the Taylor-series linearisation method [41] for complex sample design, implemented in STATA 9.1, in order to obtain correct $95 \%$ confidence intervals and $P$ values.

The first research question, "what are the prevailing attitudes towards mental health help-seeking in Europe?' was addressed by performing descriptive analyses (calculating percentages; see Table 1). The second research question, 'what are the correlates of these attitudes?' was addressed by performing multivariate regression analyses (Table 2). For the testing of country effects, effect coding was used, which allows one to test the deviation of each country from an "average European" effect, the so-called grand mean. Because the grand mean functions as a reference category, one of the six country effects does not have to be omitted during the presentation of the regression models in Table 2, as dummy coding would stipulate. The third research question, 'to what extent are these attitudes associated with actual service use for mental health problems?' was addressed by performing multivariate multinomial logistic regression analyses (Table 3). These analyses compared the two groups of service users with the respondents reporting no use of either type of care for mental health problems in the past 12 months.

\section{Results}

Attitudes towards mental health help-seeking

A total of $88.2 \%$ of the Spanish and $80.5 \%$ of the Italian respondents would probably or definitively go for professional help in case a serious emotional problem arose. In the other countries this was considerably lower, ranging from $56.8 \%$ (Belgium) to $65.4 \%$ (Germany).

A total of $73.0 \%$ of the Spanish respondents would feel somewhat or very comfortable talking about personal problems with a professional. In the other countries this varied between $43.4 \%$ (Germany) and $67.5 \%$ (the Netherlands).

A total of $90.3 \%$ of the Spanish respondents would not be very or at all embarrassed if their friends knew they were getting professional help for an emotional problem. In the other countries this ranged from $73.1 \%$ (Italy) to $81.5 \%$ (Belgium).

The respondents were less favourable about the effectiveness of professional help for serious emotional problems. Only in Spain the majority of respondents (61.4\%) held the view that professional help was considerable or much better than no help. In Italy $45.2 \%$ shared this view, and in the other countries this varied between $15.8 \%$ (the Netherlands) and $27.7 \%$ (France). Stated differently, almost a third of all respondents believed that professional care was worse than or equal to no help when faced with a serious emotional problem.

Correlates of attitudes towards mental health help-seeking

The female gender, being younger than 65 years of age, higher income, and living in Spain or Italy were significantly associated with at least two of the four attitudes towards mental health help-seeking. To be more specific, the belief that respondents would seek help when faced with a serious emotional problem was more often reported by women (compared to men), by those younger than 
Table 1 Attitudes towards mental health help-seeking in six European countries (part II sample, $N=8,796$ ), in percentages (weighted data)

\begin{tabular}{|c|c|c|c|c|c|c|c|}
\hline & $\begin{array}{l}\text { Belgium } \\
(n=1,043) \\
\%\end{array}$ & $\begin{array}{l}\text { France } \\
(n=1,436) \\
\%\end{array}$ & $\begin{array}{l}\text { Germany } \\
(n=1,323) \\
\%\end{array}$ & $\begin{array}{l}\text { Italy } \\
(n=1,779) \\
\%\end{array}$ & $\begin{array}{l}\text { The Netherlands } \\
(n=1,094) \\
\%\end{array}$ & $\begin{array}{l}\text { Spain } \\
(n=2,121) \\
\%\end{array}$ & $\begin{array}{l}\text { Total } \\
(n=8,796) \\
\%\end{array}$ \\
\hline \multicolumn{8}{|c|}{ Would go for professional help in case of a serious emotional problem } \\
\hline Definitively not go & 23.9 & 22.8 & 10.2 & 10.0 & 13.8 & 6.1 & 12.8 \\
\hline Probably not go & 19.4 & 17.4 & 24.4 & 9.6 & 21.6 & 5.6 & 16.3 \\
\hline Probably go & 28.4 & 28.5 & 41.3 & 37.7 & 37.9 & 24.2 & 34.5 \\
\hline Definitively go & 28.4 & 31.3 & 24.1 & 42.8 & 26.8 & 64.0 & 36.4 \\
\hline \multicolumn{8}{|c|}{ Would feel comfortable talking about personal problems } \\
\hline Not at all comfortable & 15.9 & 15.9 & 16.0 & 15.5 & 8.0 & 7.4 & 14.0 \\
\hline Not very comfortable & 19.1 & 22.5 & 40.6 & 17.7 & 24.5 & 19.6 & 26.6 \\
\hline Somewhat comfortable & 37.8 & 37.4 & 33.2 & 41.9 & 53.5 & 37.2 & 38.1 \\
\hline Very comfortable & 27.3 & 24.2 & 10.2 & 24.9 & 14.0 & 35.8 & 21.3 \\
\hline \multicolumn{8}{|c|}{ Would be embarrassed if friends knew about professional help } \\
\hline Very embarrassed & 3.8 & 5.8 & 5.8 & 7.5 & 2.6 & 1.6 & 5.3 \\
\hline Somewhat embarrassed & 14.8 & 14.7 & 13.3 & 19.4 & 17.4 & 8.1 & 14.4 \\
\hline Not very embarrassed & 23.5 & 22.4 & 35.7 & 27.8 & 20.3 & 20.2 & 27.4 \\
\hline Not at all embarrassed & 58.0 & 57.1 & 45.3 & 45.3 & 59.7 & 70.1 & 52.9 \\
\hline \multicolumn{8}{|c|}{ Perceived effectiveness of professional help } \\
\hline Worse than or equal to no help & 34.3 & 38.9 & 36.5 & 23.6 & 45.6 & 19.1 & 32.2 \\
\hline Somewhat better than no help & 38.9 & 33.5 & 37.4 & 31.3 & 38.6 & 19.5 & 32.8 \\
\hline Considerable better than no help & 20.8 & 22.3 & 23.1 & 32.7 & 14.2 & 34.9 & 26.1 \\
\hline Much better than no help & 6.0 & 5.4 & 3.0 & 12.5 & 1.6 & 26.5 & 8.9 \\
\hline
\end{tabular}

65 years of age (compared to those being 65 years or older), by higher income groups (compared to lower income groups), and by those living in Spain or Italy (compared to the "average" European).

These groups, except for the higher income groups, also believed professional help to be more effective in dealing with emotional problems.

The belief that respondents would feel comfortable talking about personal problems with a professional, was more often reported by higher income groups (compared to lower income groups), and by those living in Spain or Italy (compared to the "average" European).

The belief that they would not be embarrassed if friends knew about the professional help was more often reported by women (compared to men), by the highest income group (compared to the lowest income group), and by those living in Spain (compared to the "average" European). The Italian respondents were less likely than the "average" European to report that they would not be embarrassed if friends knew about the professional help, despite their positive beliefs on the other three aspects towards mental health help-seeking.

Two socio-demographic correlates were not associated with all four assessed attitudes towards mental health helpseeking: years of education and paid employment.
Two clinical correlates were significantly associated with at least two of the four attitudes towards mental health help-seeking: respondents with a mood disorder (compared to ones without such disorder) and those who had previously used care for their mental health problems (compared to ones without previous service use) more often held the beliefs that they would seek help when faced with a serious emotional problem and that they would feel comfortable talking about personal problems with a professional.

The diagnosed group also believed professional help to be more effective in dealing with emotional problems. Surprisingly, previous service use was not associated with perceived effectiveness of professional help. Additional descriptive analyses (not tabulated) revealed that the respondents with previous mental health care use experiences were more sceptical about professional help compared to the actual mental health care users: respectively 30 and $19 \%$ hold the view that professional help was worse than or equal to no help.

The respondents who had previously used mental health care, more often held the belief that they would not be embarrassed if friends knew about the professional help sought.

Four clinical correlates were not associated with all four assessed attitudes towards mental health help-seeking: 


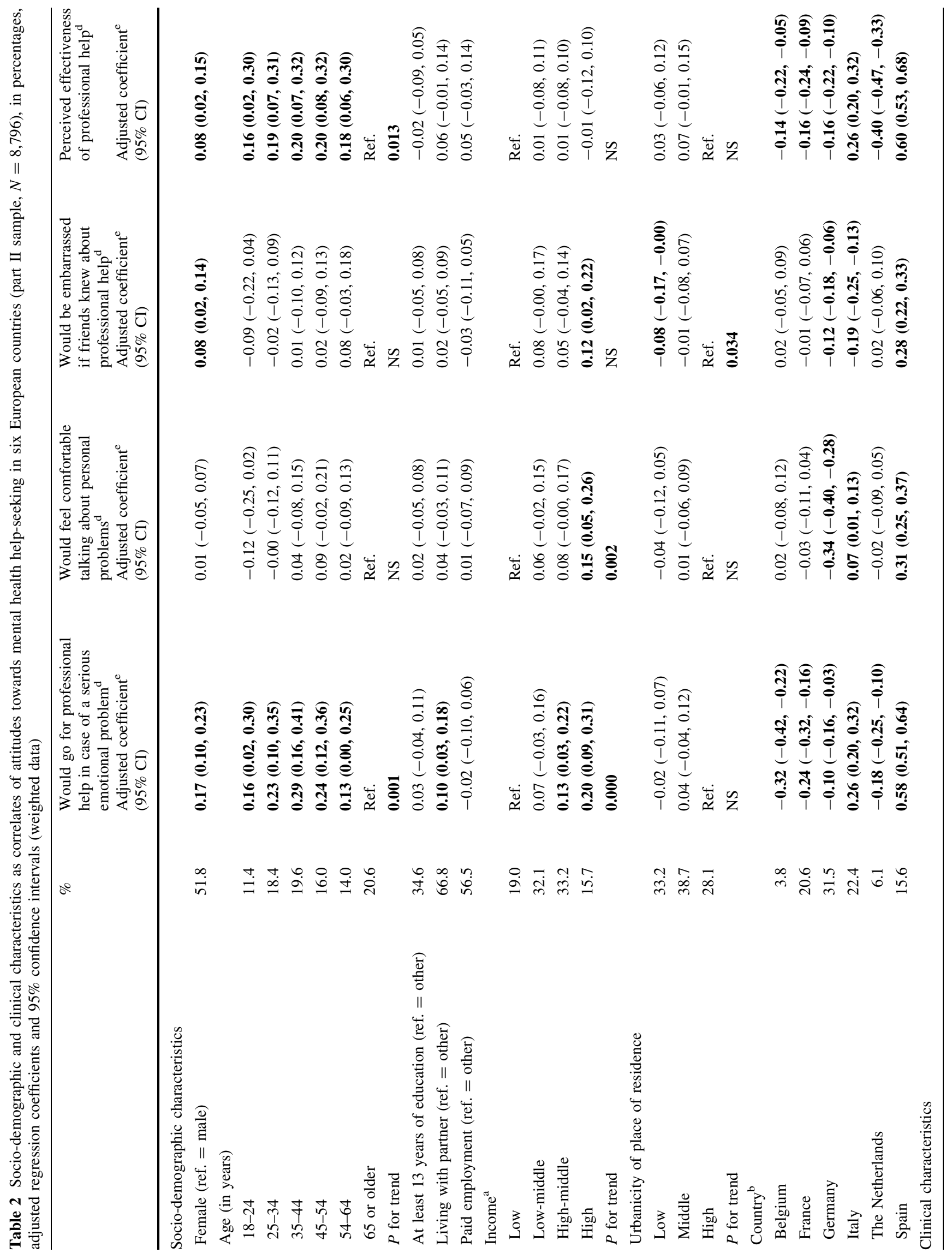




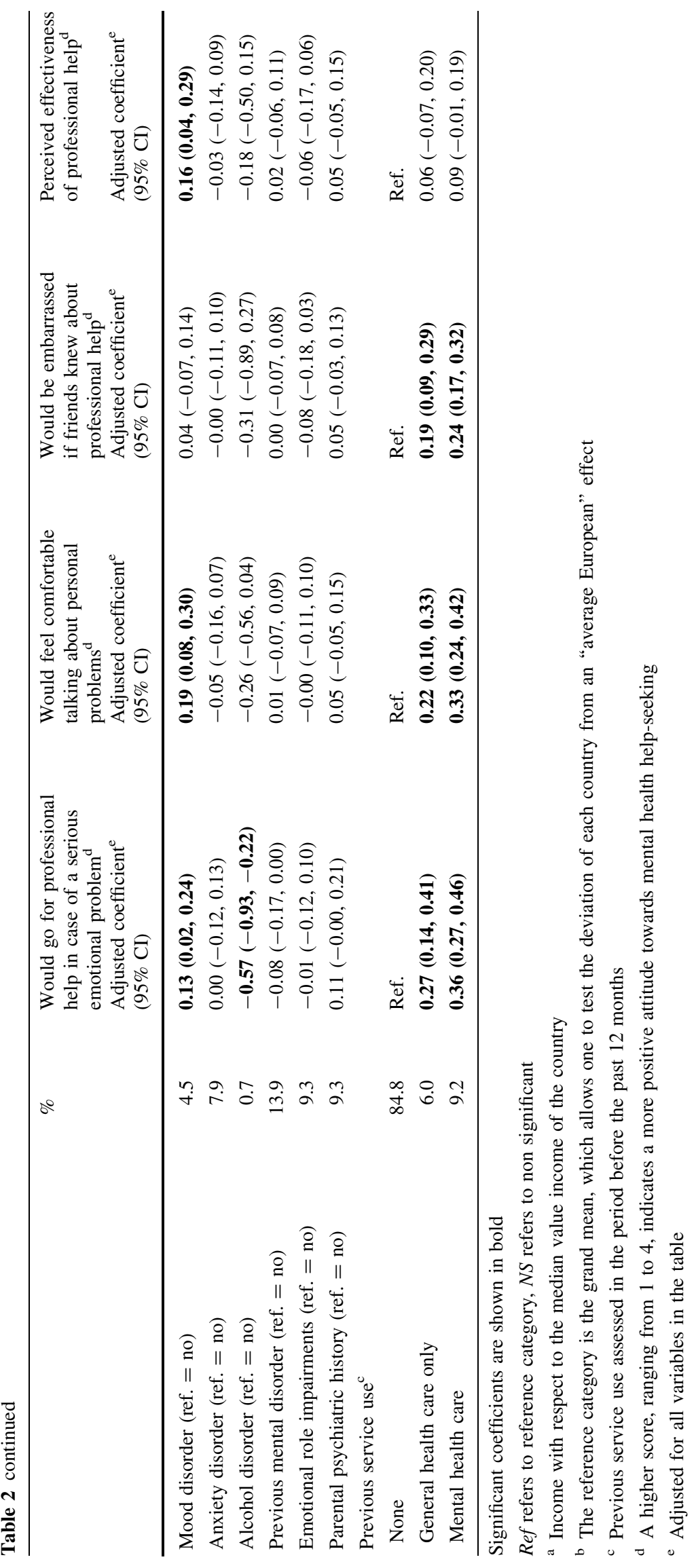


Table 3 Attitudes towards mental health help-seeking as correlates of service use for mental health problems in six European countries (part II sample, $N=8,796$ ), in adjusted relative risk ratios and 95\% confidence intervals (weighted data)

\begin{tabular}{|c|c|c|}
\hline & \multicolumn{2}{|c|}{ Service use for mental health problems } \\
\hline & $\begin{array}{l}\text { General health care only } \\
\text { Adjusted RRR }(95 \% \mathrm{CI})^{\mathrm{b}}\end{array}$ & $\begin{array}{l}\text { Mental health care } \\
\text { Adjusted RRR }(95 \% \text { CI })^{\mathrm{b}}\end{array}$ \\
\hline Would go for professional help in case of a serious emotional problem ${ }^{a}$ & $1.34(1.13,1.60)$ & $2.97(2.11,4.19)$ \\
\hline Would feel comfortable talking about personal problems ${ }^{\mathrm{a}}$ & $1.22(1.02,1.47)$ & $1.88(1.52,2.32)$ \\
\hline Would be embarrassed if friends knew about professional help ${ }^{a}$ & $1.14(0.94,1.38)$ & $1.31(1.04,1.65)$ \\
\hline Perceived effectiveness of professional help ${ }^{a}$ & $1.24(1.00,1.54)$ & $1.62(1.35,1.94)$ \\
\hline
\end{tabular}

The reference category is no help sought in health care. Results of four separately performed regression analyses. Significant relative risk ratios are shown in bold

Ref refers to reference category

${ }^{a}$ A higher score, ranging from 1 to 4 , indicates a more positive attitude towards mental health help-seeking

b Adjusted for socio-demographic variables (gender, age, education, partner status, employment status, income, urbanicity of place of residence) and clinical characteristics (12 months mood disorder, 12 months anxiety disorder, 12 months alcohol disorder, previous mental disorder, emotional role impairments, parental psychiatric history, previous service use)

having an anxiety disorder, having a previous mental disorder, experiencing emotional role impairments, and having at least one parent with a psychiatric history.

Attitudes towards mental health help-seeking as correlates of actual service use

Attitudes towards mental health help-seeking were found to be significantly associated with service use. After adjustment for socio-demographics and clinical characteristics, such as presence of a mental disorder and previous service use, two of the four attitudes were associated with general health care use: beliefs that respondents would seek help when faced with a serious emotional problem and that they would feel comfortable talking about personal problems with a professional significantly increased the chance of using general health care only. The associated relative risk ratios varied between 1.22 and 1.34 .

All four attitudes were associated with mental health care use. The adjusted relative risk ratios varied from 1.31 (for the belief that they would not be embarrassed if friends knew about the professional help) to 2.97 (for the belief that respondents would seek help when faced with a serious emotional problem) for the use of mental health care.

\section{Discussion}

\section{Strengths and limitations}

This population study is the first that investigated attitudes towards mental health help-seeking on a large scale in Europe, and to what extent such attitudes are associated with variations in service use, after controlling for mental disorder, previous service use and various other correlates of service use.

Although the study was representative for the general population, non-responders may have different attitudes towards mental health help-seeking and may use health care services differently from responders. It is however difficult to guess how this might have affected the results.

A universal standard for how attitudes towards mental health help-seeking can best be measured is not available. In the present study questions on this topic were used which were developed for the WMH-CIDI and were based on previous population studies explaining variations in service use [32-35] such as the National Comorbidity Survey [36]. Despite that these questions are frequently used in various countries all over the world, research on the validity and reliability of these questions is still in development.

It goes without saying that the cross-sectional nature of the data does not allow a strict causal interpretation of the results. The association found between previous service use and attitude towards mental health help-seeking supports the hypothesis that experience with health care influences people's attitude towards it. Longitudinal studies are needed to confirm the theoretical notion that service use (behaviour) is also influenced by people's prior attitude towards mental health help-seeking. Indications for this relationship were found in the present study: after adjustment for previous service use and other variables, all four attitudes were still associated with mental health care use.

\section{Discussion of findings}

To our knowledge, only few studies have been published on correlates of attitudes towards mental health help- 
seeking and to what extent such attitudes are associated with service use. In addition, the majority used different definitions of attitudes and were not based on a large representative sample, which makes comparison between these studies and with our findings difficult.

In the present study, taking all six countries together, the majority of respondents would probably or definitively go for professional help in case a serious emotional problem would arise $(70.9 \%)$, would feel reasonably comfortable talking about personal problems with a professional $(59.4 \%)$ and would not be embarrassed if their friends knew they were getting professional help for an emotional problem $(80.3 \%)$. However, they were less favourable about the effectiveness of professional help for serious emotional problems. 32.2\% indicated that professional help was worse than or equal to no help. These findings must be taken as a very serious public health issue. We will discuss this issue below.

These attitudes towards mental health help-seeking differed significantly between the six European countries. The Spanish respondents were the most positive with respect to all four attitudes towards mental health helpseeking, whereas those living in Germany were the least positive on all aspects of seeking mental health care. It is difficult to explain these differences. One possible explanation is that the Spanish reported a lower level of unmet need compared to all respondents in the six countries together [42], implying that in Spain the more serious cases had a higher chance of receiving mental health care. But this cannot explain all differences found, because the majority of the respondents had never received mental health care at the time of the interview.

In the multivariate analysis four socio-demographic characteristics were associated with at least two of the four attitudes towards mental health help-seeking: female gender, being younger than 65 years of age, higher income and living in Spain or Italy. Earlier studies also found more favourable attitudes among women [22, 23], and younger people [23, 24]. Higher education was not associated with more favourable attitudes towards mental health helpseeking. This seemed to contrast with studies, which found lower levels of tolerance towards psychiatric patients among lower educated people [12, 13]. However, in these studies the analyses were not adjusted for the influence of other socio-demographic variables and clinical characteristics.

Certain patient groups did differ in their attitudes towards mental health help-seeking compared to healthy individuals. This was true for respondents with a mood disorder and for those with previous (mental) health care experiences, but not for those with an anxiety disorder. Previous studies also found more positive beliefs among people who had prior experience with mental health care
[19-21]. The respondents with an alcohol disorder held significantly less often the belief that they would seek help when faced with a serious emotional problem compared to those without an alcohol disorder. The ones with an alcohol disorder would also feel less comfortable talking about personal problems with a professional, would be more often embarrassed if friends knew about the help, and were less positive about the effectiveness of professional help compared to those without an alcohol disorder, although these differences did not reach significance. These negative attitudes towards mental health help-seeking of those with an alcohol disorder are in line with the finding that adults with an alcohol disorder avoid consulting a general practitioner and use mental health care equally often compared to those without such disorder [43, 44].

Previous studies found more positive beliefs among people who were more familiar with mental illness [12, 13]. In the present study, previous mental disorder as well as parental psychiatric history, which could be seen as indications that the respondent is more familiar with mental health problems were not associated with one of the attitudes towards mental health help-seeking.

All four attitudes were associated with mental health care use, also after adjustment for the presence of a mental disorder, previous service use and other correlates of service use. This is in line with three of four previous studies $[25,28,36]$ we found on this subject, and with studies which focussed on reasons given by people with emotional problems for not seeking professional help, even though they felt they needed it [32, 33, 35, 45]. These studies found that people mainly tend to offer attitude-related reasons for foregoing care, such as: (1) I wanted to solve my problems on my own, (2) I thought the problem would go away by itself, (3) I had no confidence in the care providers I would have had to go to and (4) I thought no one could help me anyway. Practical considerations, such as lack of time or money, were less likely mentioned.

\section{Implications}

Almost a third of all respondents believed that professional care was worse than or equal to no help when faced with a serious emotional problem. This rather negative belief is in line with previous research $[9,46]$. In the present study, respondents with previous mental health care experiences were equally sceptical, but actual mental health care users were more positive; $30 \%$ respectively $19 \%$ hold the view that professional help was worse than or equal to no help. One explanation for these figures is that patients do not always receive appropriate treatment. Another paper based on ESEMeD-data revealed that the diagnosis and treatment of mood and anxiety disorders in the six European countries remain suboptimal [47]. 
This calls for serious action aimed to improve the visibility and credibility of the mental health care sector. First, public health campaigns are needed to inform the public about the treatments available for mental health problems. In Germany, a campaign informing the public about the causes and treatments of depression showed some limited but promising results [48]. Second, more research is needed to determine the evidence-base of all treatments applied in the mental health care sector. Third, health care managers and professionals should be stimulated to actually apply the evidence-based treatments available, and to learn from patients' experiences with the care provided.

Acknowledgments This research was funded by the Netherlands Mental Health Fund (Fonds Psychische Gezondheid). The ESEMeD project was funded by the European Commission (Contracts QLG51999-01042; SANCO 2004123), the Piedmont Region (Italy), Fondo de Investigación Sanitaria, Instituto de Salud Carlos III, Spain (FIS 00/0028-02), Ministerio de Ciencia y Tecnología, Spain (SAF 2000158-CE), Departament de Salut, Generalitat de Catalunya, Spain, and other local agencies and by an unrestricted educational grant from GlaxoSmithKline.

Open Access This article is distributed under the terms of the Creative Commons Attribution Noncommercial License which permits any noncommercial use, distribution, and reproduction in any medium, provided the original author(s) and source are credited.

\section{References}

1. Angermeyer MC, Dietrich S (2006) Public beliefs about and attitudes towards people with mental illness: a review of population studies. Review article. Acta Psychiatr Scand 113:163-179

2. Jorm AF, Korten AE, Jacomb PA, Christensen H, Rodgers B, Pollitt P (1997) Mental health literacy: a survey of the public's ability to recognise mental disorders and their beliefs about the effectiveness of treatment. Med J Aust 166:182-186

3. Lauber C, Nordt C, Falcato L, Rössler W (2003) Do people recognise mental illness? Factors influencing mental health literacy. Eur Arch Psychiatry Clin Neurosci 253:248-251

4. De Toledo Piza Peluso E, De Araujo Peres C, Luis Blay S (2008) Public conceptions of schizophrenia in urban Brazil. Soc Psychiatry Psychiatr Epidemiol 43:792-799

5. Angermeyer MC, Matschinger H (1996) Public attitude towards psychiatric treatment. Acta Psychiatr Scand 94:326-336

6. Jorm AF, Korten AE, Jacomb PA et al (1997) Helpfulness of interventions for mental disorders: beliefs of health professionals compared with the general public. Br J Psychiatry 171:233-237

7. Magliano L, Fiorillo A, de Rosa C, Malangone C, Maj M (2004) Beliefs about schizophrenia in Italy: a comparative nationwide survey of the general public, mental health professionals, and patients' relatives. Can J Psychiatry 49:322-330

8. Angermeyer MC, Matschinger H (1997) Social distance towards the mentally ill: results of representative surveys in the Federal Republic of Germany. Psychol Med 27:131-141

9. Jorm AF, Angermeyer MC, Katschnig H (2000) Public knowledge of and attitudes to mental disorders: a limiting factor in the optimal use of treatment services. In: Andrews G, Henderson S (eds) Unmet need in psychiatry. Problems, resources, responses. Cambridge University Press, Cambridge, pp 399-413
10. Priest RG, Vize C, Roberts A, Roberts M, Tylee A (1996) Lay people's attitudes to treatment of depression: results of opinion poll for defeat depression campaign just before its launch. Br Med J 313:858-859

11. Norman RMG, Sorrentino RM, Windell D, Manchanda R (2008) The role of perceived norms in the stigmatization of mental illness. Soc Psychiatry Psychiatr Epidemiol 43:851-859

12. Riedel-Heller SG, Matschinger H, Angermeyer MC (2005) Mental disorders-who and what might help? Help-seeking and treatment preferences of the lay public. Soc Psychiatry Psychiatr Epidemiol 40:167-174

13. Shulman N, Adams B (2002) A comparison of Russian and British attitudes towards mental health problems in the community. Int J Soc Psychiatry 48:266-278

14. Angermeyer MC, Matschinger H (2004) Public attitudes towards psychotropic drugs: have there been any changes in recent years? Pharmacopsychiatry 37:152-156

15. Beck M, Matschinger H, Angermeyer MC (2003) Social representations of major depression in West and East Germany. Do differences still persist 11 years after reunification? Soc Psychiatry Psychiatr Epidemiol 38:520-525

16. Barney LJ, Griffiths KM, Jorm AF, Christensen H (2006) Stigma about depression and its impact on help-seeking intentions. Aust N Z J Psychiatry 40:51-54

17. Segal DL, Coolidge FL, Mincic MS, O'Riley A (2005) Beliefs about mental illness and willingness to seek help: a cross-sectional study. Aging Ment Health 9:363-367

18. Vogel DL, Wade NG, Hackler AH (2007) Perceived public stigma and the willingness to seek counseling: the mediating roles of self-stigma and attitudes toward counseling. J Couns Psychol 54:40-50

19. Hatchet GT (2006) Additional validation of the attitudes toward seeking professional psychological help scale. Psychol Rep 98:279-284

20. Smith LD, Peck PL (2002) Comparison of medical students, medical school faculty, primary care physicians, and the general population on attitudes toward psychological help-seeking. Psychol Rep 91:1268-1272

21. Wang JL, Patten SB (2007) Perceived effectiveness of mental health care provided by primary-care physicians and mental health specialists. Psychosom J Consult Liaison Psychiatry 48:123-127

22. Leong FTL, Zachar P (1999) Gender and opinions about mental illness as predictors of attitudes toward seeking professional psychological help. Br J Guid Couns 27:123-132

23. Mackenzie CS, Gekoski WL, Knox VJ (2006) Age, gender, and the underutilization of mental health services: the influence of help-seeking attitudes. Aging Ment Health 10:574-582

24. Robb C, Haley WE, Becker MA, Polivka LA, Chwa H-J (2003) Attitudes towards mental health care in younger and older adults: similarities and differences. Aging Ment Health 7:142-152

25. Judd F, Jackson H, Komiti A, Murray G, Fraser C, Grieve A, Gomez R (2006) Help-seeking by rural residents for mental health problems: the importance of agrarian values. Aust $\mathrm{N} \mathrm{Z} \mathrm{J}$ Psychiatry 40:769-776

26. Komiti A, Judd F, Jackson H (2006) The influence of stigma and attitudes on seeking help from a GP for mental health problems: a rural context. Soc Psychiatry Psychiatr Epidemiol 41:738-745

27. Jorm AF, Christensen H, Korten AE, Jacomb PA, Rodgers B (2000) Public beliefs about the helpfulness of interventions for depression: effects on actions taken when experiencing anxiety and depression symptoms. Aust N Z J Psychiatry 34:619-626

28. Vanheusden K (2007) Mental health problems and barriers to service use in Dutch young adults. Optima Grafische Communicatie, Rotterdam

29. The ESEMeD/MHEDEA 2000 Investigators (Scientific Committee: Alonso J, Angermeyer M, Bernert S, Bruffaerts R, Brugha TS, 
Bryson H, de Girolamo G, de Graaf R, Demyttenaere K, Gasquet I, Haro JM, Katz SJ, Kessler RC, Kovess V, Lépine JP, Ormel J, Polidori G, Russo LJ, Vilagut G. Additional investigators: Almansa J, Arbabzadeh-Bouchez S, Autonell J, Bernal M, Buist-Bouwman MA, Codony M, Domingo-Salvany A, Ferrer M, Joo SS, MartínezAlonso M, Matschinger H, Mazzi F, Morgan Z, Morosini P, Palacín C, Romera B, Taub N, Vollebergh WAM) (2004) Sampling and methods of the European Study of the Epidemiology of Mental Disorders (ESEMeD) project. Acta Psychiatr Scand 109(Suppl 420):8-20

30. Kessler RC, Ustun TB (2004) The World Mental Health (WMH) Survey Initiative Version of the World Health Organization (WHO) Composite International Diagnostic Interview (CIDI). Int J Methods Psychiatr Res 13:93-121

31. Haro JM, Arbabzadeh-Bouchez S, Brugha TS, de Girolamo G, Guyer ME, Jin R, Lepine JP, Mazzi F, Reneses B, Vilagut G, Sampson NA, Kessler RC (2006) Concordance of the Composite International Diagnostic Interview Version 3.0 (CIDI 3.0) with standardized clinical assessments in the WHO World Mental Health Surveys. Int J Methods Psychiatr Res 15:167-180

32. Hornblow AR, Bushnell JA, Wells JE, Joyce PR, Oakley-Browne MA (1990) Christchurch psychiatric epidemiology study: use of mental health services. N Z Med J 103:415-417

33. Meltzer H, Bebbington $P$, Brugha T, Farrell M, Jenkins R, Lewis G (2000) The reluctance to seek treatment for neurotic disorders. J Ment Health 9:319-327

34. Bijl RV, Ravelli A (2000) Psychiatric morbidity, service use and need for care in the general population: results of the Netherlands Mental Health Survey and Incidence Study. Am J Public Health 90:602-607

35. Wells JE, Robins LN, Bushnell JA et al (1994) Perceived barriers to care in St Louis (USA) and Christchurch (NZ): reasons for not seeking professional help for psychological distress. Soc Psychiatry Psychiatr Epidemiol 29:155-164

36. Mojtabai R, Olfson M, Mechanic D (2002) Perceived need and help-seeking in adults with mood, anxiety, or substance use disorders. Arch Gen Psychiatry 59:77-84

37. Ten Have M (2004) Care service use for mental health problems in the general population: trends and explanations. Grafisch bedrijf Ponsen \& Looijen b.v, Wageningen
38. Ware JE, Kosinski M, Keller SD (1995) SF-12. How to score the SF-12 physical and mental health summary scales. The Health Institute, Boston

39. Ware JE, Kosinski M, Keller SD (1994) SF-36 physical and mental health summary scales: a user's manual. The Health Institute, Boston

40. Ware J, Kosinski M, Keller SD (1996) A 12-item short-form health survey: construction of scales and preliminary tests of reliability and validity. Med Care 34:220-233

41. Wolter KM (1985) Introduction to variance estimation. Springer, New York

42. Alonso J, Codony M, Kovess V, Angermeyer MC, Katz SJ, Haro JM, de Girolamo G, de Graaf R, Demyttenare K, Vilagut G, Almansa J, Lepine JP, Brugha TS (2007) Population level of unmet need for mental health care in Europe. Br J Psychiatry 190:299-306

43. The ESEMeD/MHEDEA 2000 Investigators (2004) Use of mental health services in Europe: results from the European Study of the Epidemiology of Mental Disorders (ESEMeD) project. Acta Psychiatr Scand 109(Suppl 420):47-54

44. Ten Have M, de Graaf R, Vollebergh W, Beekman A (2004) What depressive symptoms are associated with the use of care services? Results from the Netherlands Mental Health Survey and Incidence Study (NEMESIS). J Affect Disord 80:239-248

45. Sareen J, Jagdeo A, Cox BJ, Clara I, ten Have M, Belik S-L, de Graaf R, Stein MB (2007) Perceived barriers to mental health service utilization in the United States, Ontario, and the Netherlands. Psychiatr Serv 58:357-364

46. Angermeyer MC, Matschinger H (2005) Have there been any changes in the public's attitudes towards psychiatric treatment? Results from representative population surveys in Germany in the years 1990 and 2001. Acta Psychiatr Scand 111:68-73

47. Fernandez A, Haro JM, Martinez-Alonsko M, Demyttenaere K, Brugha TS, Autonell J, de Girolamo G, Bernert S, Lepine JP, Alonso J (2007) Treatment adequacy for anxiety and depressive disorders in six European countries. Br J Psychiatry 190:172-173

48. Hegerl U, Althaus D, Stefanek J (2003) Public attitudes towards treatment of depression: effects of an information campaign. Pharmacopsychiatry 36:288-291 